\title{
Use of Fibrinolysis in Acute Pulmonary Embolism
}

\author{
Alicia M. Pilarski $\cdot$ Shanna Paul
}

Published online: 11 April 2014

(c) Springer Science+Business Media New York 2014

\begin{abstract}
Acute pulmonary embolism (PE) is a serious medical condition frequently diagnosed in the emergency department. It is a diagnosis which can be difficult to make, yet requires prompt treatment because of its high morbidity and mortality. There are various treatment options available that are chosen based on severity of disease (low-risk $\mathrm{PE}$, submassive $\mathrm{PE}$, and massive $\mathrm{PE}$ ). In this article, we will focus on determining the level of severity of acute pulmonary embolism as well as the recommended treatment for patients within these three categories. Specifically, we will focus on the use of fibrinolysis in acute PE.
\end{abstract}

Keywords PE - Acute PE - Pulmonary embolism . Fibrinolysis in PE - Treatment of PE - Anticoagulation in PE

\section{Introduction}

Acute PE has an incidence that ranges from 23 to 69 per 100,000 population per year [1•]. It is a condition that carries significant morbidity and mortality, and prompt identification and treatment are necessary for favorable outcomes. There are three main classifications of PE that are based on clinical presentation: massive PE, submassive $\mathrm{PE}$, and low-risk PE, and treatment is chosen based on this classification [2•]. The preferred and best available options

\footnotetext{
A. M. Pilarski $(\bowtie) \cdot$ S. Paul

Department of Emergency Medicine, Medical College of

Wisconsin, 9200W. Wisconsin Ave, Milwaukee, WI 53226,

USA

e-mail: apilarski@mcw.edu

S. Paul

e-mail: spaul@mcw.edu
}

for treatment of acute PE include anticoagulation and systemic fibrinolysis; less frequently used treatments include catheter-directed fibrinolysis and surgical embolectomy. Both risks and benefits must be weighed when considering each type of therapy, as well as which resources are available at each institution.

\section{Diagnosis of Acute Pulmonary Embolism}

The diagnosis of acute pulmonary embolism includes risk stratification in patients who present with new symptoms of shortness of breath, chest pain, syncope, or sustained hypotension without an alternative obvious cause [2•]. Patients should all initially be assessed for hemodynamic stability. Unstable patients with concern for acute pulmonary embolism are those who are in shock or have a systolic blood pressure less than $90 \mathrm{mmHg}$, without arrhythmia, hypovolemia, sepsis, or another identifiable cause. Those considered to be unstable require immediate radiologic diagnostic studies to assess for pulmonary embolism or secondary findings of pulmonary embolism. In a stable patient, risk stratification includes clinical decision rules such as Well's criteria and the pulmonary embolism rule-out criteria (PERC), which help to classify patients with suspected pulmonary embolism into several categories of pretest probability. $D$-dimer testing is also of utility in patients who have low or intermediate risk for pulmonary embolism, and if negative, can help avoid any further investigation with radiologic studies [2•]. $D$-dimer testing can be elevated in patients with cancer, pregnant women and hospitalized and elderly patients [3], so it should be used in the appropriate setting. If a stable patient has a positive $D$-dimer value, or has high probability for pulmonary embolism based on risk stratification, they 
Table 1 Identifying submassive PE (adapted from reference [7•])

\begin{tabular}{l} 
Patient's clinical presentation \\
General appearance (acutely ill, confused) \\
Hypotension (relative or absolute) \\
Tachycardia/tachypnea \\
Electrocardiography \\
Tachycardia \\
RV strain patterns \\
Echocardiography \\
RV enlargement/hypokinesis \\
Right atrial enlargement \\
Clot in transit \\
Patent foremen ovale or other shunt \\
Computed tomographic angiography \\
RV enlargement \\
Embolic burden/proximal extent of emboli \\
Presence/extent of venous thrombosis (if CT venogram is \\
performed) \\
Biomarkers \\
Serum troponin \\
Brain natriuretic peptide/pro-BNP \\
\hline
\end{tabular}

should undergo a multidetector CT study of the chest [2•]. In cases where a multidetector $\mathrm{CT}$ is not available, the patient has renal failure, or if the patient has a contrast dye allergy, ventilation-perfusion (V/Q) scanning is preferred [4]. If a patient is too unstable for $\mathrm{CT}$, use of transthoracic or transesphogeal echocardiography is indicated to assess for right ventricular dysfunction [2•]. Multidetector CT testing has a $97 \%$ sensitivity for acute PE and is the preferred choice for evaluation of patient with suspected PE [2•]. A normal V/Q scan has a negative predictive value of $97 \%$, but is diagnostic in only $30-50 \%$ of patients with suspected PE [5]. Magnetic resonance angiography does not have sufficient sensitivity for detection of acute PE and can have a high rate of technically inadequate images [6] (Table 1).

\section{Risk Stratification of Acute Pulmonary Embolism}

Once the diagnosis of acute pulmonary embolism has been established, it is important to risk-stratify the patient to help guide medical management, as well as further understand the patient's predicted outcomes. The first category of stratification is stable versus unstable, and this is likely apparent even before the diagnosis is made. In patients who are unstable, resuscitation, anti-coagulation, and fibrinolysis in the absence of absolute contraindications (Table 4) are typically agreed upon given the high mortality of these patients [7•]. However, in the stable patient, or borderline patient who intermittently displays signs of instability (transient drops in systolic blood pressure and/or oxygenation, waxing mental status, syncope, etc.), guidelines to management are debated. Recent studies, however, suggest that patients in this intermediate-risk group may benefit from similar treatment as those in the unstable group. The main classifications of patients with acute PE are defined by the European Society of Cardiology (ESC) and the American College of Chest Physicians (ACCP) as massive (high-risk), submassive (intermediaterisk) and low-risk pulmonary embolism [12, 13].

\section{Massive Pulmonary Embolism}

Typically, patients in this category have more consistent findings with hemodynamic instability (systolic blood pressure less than $90 \mathrm{mmHg}$, altered mental status, and cardiopulmonary arrest). Massive pulmonary embolism is also defined as extensive clot burden as determined by computed tomography. Mortality approaches $70 \%$ in patients with acute PE who suffer cardiopulmonary arrest, $30 \%$ in patients with cardiogenic shock, and $15 \%$ in patients with hypotension [8-10]. Data from randomized (mostly small) trials showed that fibrinolysis plus anticoagulation in hemodynamically unstable patients result in significant reduction of death rates and symptomatic recurrence of PE [11]. Guidelines of both the ESC and the ACCP strongly recommend the use of fibrinolysis and anticoagulation in hypotensive patients with high-risk PE $[12,13]$.

\section{Submassive Pulmonary Embolism}

Patients in this category can be described as hemodynamically stable but with abnormal right ventricular (RV) function and/or injury to the myocardium as a result of acute pressure overload $[12,14]$. Stratification of patients into this category involves several factors: clinical status of the patient, electrocardiography, echocardiography, CT angiography, and biomarkers such as troponin and brain natriuretic peptide (BNP).

Of the listed factors, the most significant is RV function as determined on echocardiography. When performed and interpreted by an expert, the echo can determine RV size and function and can directly correlate to cardiogenic shock and mortality. Concerning findings that increase mortality rate include enlarged and/or hypokinetic RV with an interventricular septum that compromises left ventricular filling (RV collapse). These findings have been shown to be independent predictors of 30-day mortality in hemodynamically stable patients $[15,16]$. 
RV enlargement and clot burden can also be evaluated on computed tomographic angiography and can also help guide treatment. An increased right to left ventricle ration of $\geq 1$ suggests $\mathrm{RV}$ dysfunction on $\mathrm{CT}$ has been shown to predict mortality $[17,18]$.

Other factors that have been associated with increased RV compromise include an increased BNP and increased troponin $\mathrm{T}$ and $\mathrm{I}$. One meta-analysis demonstrated a fivefold increase in short-term mortality with elevation of the troponin level [19], and appears to predict outcome for patients who are hemodynamically stable at presentation. Regarding BNP and pro-BNP, one study showed increased risk of an adverse in-hospital outcome as compared to patients with normal levels [20]. Normal BNP and proBNP levels show a nearly $100 \%$ negative predictive value for an adverse outcome in hemodynamically stable patients with PE.

Combining these factors together when risk-stratifying patients with acute PE can further identify hemodynamic stable patients (submassive/intermediate-risk patients) at risk of death or major clinical complications [21, 22].

\section{Low Risk Pulmonary Embolism}

Patients in this category have a diagnosis of PE, but have no significant right heart strain patterns or any other signs of instability (normal blood pressure, adequate oxygenation, baseline mental status).

\section{Treatment of Acute Pulmonary Embolism}

The various treatment options for PE include anticoagulation, systemic fibrinolysis, catheter-directed fibrinolysis, and surgical embolectomy [2•], although catheter-directed fibrinolysis and surgical embolectomy are rarely used in the clinical setting. Patients presenting with acute pulmonary embolism should be treated with analgesia and supplemental oxygen when indicated. Short-term anticoagulation and long-term anticoagulation with vitamin $\mathrm{K}$ antagonists are also utilized in the majority of patients with acute pulmonary embolism [2•].

\section{Anticoagulation}

Most patients with acute pulmonary embolism qualify for immediate anticoagulation with short-term agents. Various treatment options include unfractionated heparin, enoxaparin, and fondaparinux. Unfractionated heparin is given as an initial bolus (80 IU per $\mathrm{kg}$ ) followed by continuous infusion at $18 \mathrm{IU}$ per $\mathrm{kg}$. Enoxaparin is dosed at $1 \mathrm{mg} / \mathrm{kg}$
Table 2 Doses of anticoagulant therapy [28]

\begin{tabular}{ll}
\hline Anticoagulant & Dose \\
\hline Unfractionated heparin & Bolus $80 \mathrm{IU} / \mathrm{kg}$ \\
& Continuous $18 \mathrm{IU} / \mathrm{kg}$ \\
Enoxaparin & $1 \mathrm{mg} / \mathrm{kg}$ twice daily \\
Fondaparinux & $<50 \mathrm{~kg}-5 \mathrm{mg}$ \\
& $50-100 \mathrm{~kg}-7.5 \mathrm{mg}$ \\
& $>100 \mathrm{~kg}-10 \mathrm{mg}$ \\
\hline
\end{tabular}

given twice daily and fondaparinux is weight-dependent ( $5 \mathrm{mg}$ for $<50 \mathrm{~kg}, 7.5 \mathrm{mg}$ for $50-100 \mathrm{~kg}$, and $10 \mathrm{mg}$ for $>100 \mathrm{~kg}$ ) (Table 2 ; [2•]). The low molecular weight heparins, such as enoxaparin and fondaparinux, are favored in the majority of patients; however, they are contraindicated in patients with renal failure. Therefore, in patients with renal disease, unfractionated heparin is the drug of choice. In those where fibrinolysis is being considered, unfractionated heparin should be considered given it is short acting mechanism of action and its ability to be easily reversed [7•]. The need to stop anticoagulation during administration of fibrinolysis has been recommended, although there is no evidence to support this practice [7•]. Patients with low-risk PE typically only require anticoagulation to treat their disease, unless the patient has contraindications to anticoagulation. In those cases, an inferior vena cava (IVC) filter may be a viable option to prevent any further clot burden.

\section{Fibrinolysis}

Patients classified as having massive pulmonary embolism with hemodynamic instability, or who present in cardiac arrest from massive PE, warrant immediate treatment with fibrinolysis. There is evidence of significant benefit in this population of patients [23]. In patients with severe massive pulmonary embolism, there are generally no absolute contraindications to fibrinolytics [23].

The use of fibrinolytic therapy in submassive PE remains a topic of debate. It has been shown that patients with submassive PE who have evidence of right ventricular dysfunction (RVD), but who are otherwise hemodynamically stable, have a higher mortality rate than submassive PE without RVD (4 \% compared to $0.9 \%$ ) [24]. When RVD is present, fibrinolysis has been shown to more rapidly restore RV function and pulmonary artery perfusion by rapidly decreasing clot burden [23-25]. Additionally, the rate of recurrent $\mathrm{PE}$ has been shown to be decreased in those receiving fibrinolytics. One potential sequelae of PE is the development of chronic thromboembolic pulmonary hypertension (CTEPH). Studies have shown that 
pulmonary artery systolic pressure has a more significant decrease at 6 months following administration of fibrinolysis versus heparin alone [26]. Whether the development of CTEPH can be prevented with the use of fibrinolytic therapy is currently being researched [24], but is something to be considered. Despite improvement in RVD and decreased risk for recurrent $\mathrm{PE}$, fibrinolytics offer no mortality benefit in submassive PE [23]. The current ESC and AHA guidelines for submassive PE suggest using fibrinolytics on a case by case basis in those without elevated risk of bleeding (class IIb evidence) [24].

The pulmonary embolism fibrinolysis (PEITHO) trial, a large, multicenter, prospective study that is currently in publication, studied the effects of tenecteplase plus heparin versus heparin alone in treatment of submassive PE with RVD. The primary outcomes were death from any cause or hemodynamic collapse within 7 days. The study, although not yet published, has demonstrated a reduction in the primary endpoint in those treated with tenecteplase plus heparin versus heparin alone. However, the risk for major bleeding was also significantly increased in the tenecteplase group, especially in those older than 75 [11]. This study suggests that using fibrinolysis in carefully selected patients, who are low risk for bleeding, would be beneficial.

In summary, fibrinolysis should be considered for submassive PE in patients with high clot burden, elevated troponin and BNP, with evidence of RVD on echocardiography, and refractory hypoxia [2•, 23, 24]. In all patients with submassive PE, a risk/benefit analysis should also be done to further determine whether fibrinolysis is contraindicated. The absolute and relative contraindications to fibrinolysis are listed in Tables 3 and 4.

The most well-studied options for fibrinolysis include recombinant tPA, streptokinase, and recombinant human urokinase [7•]. The recommended dose of recombinant human tPA is $100 \mathrm{mg}$ over $2 \mathrm{~h}$ ( $10 \mathrm{mg}$ bolus followed by $90 \mathrm{mg}$ infusion). The recommended dose of streptokinase is $250,000 \mathrm{IU}$ administered over $30 \mathrm{~min}$ and for urokinase is a loading dose of $4,400 \mathrm{IU} / \mathrm{kg}$ over $10 \mathrm{~min}(90 \mathrm{~mL} / \mathrm{h})$ followed by $4,400 \mathrm{IU} / \mathrm{kg} / \mathrm{h}(15 \mathrm{~mL} / \mathrm{h})$ continuous infusion for $12 \mathrm{~h}$ [28]. Tenecteplase, a fibrinolytic used for acute myocardial infarction, has shown efficacy in reducing RVD in submassive PE, although is not FDA-approved for acute PE [27]. The dose used in the study was the same dose used for acute MI (weight-dependent, 30-50 mg bolus over $5 \mathrm{~s}$ ) $[27,28]$. This is also the drug used in the PEITHO trial. Another option to consider is reduced dose of tPA, $50 \mathrm{mg}$ over $2 \mathrm{~h}$ versus $100 \mathrm{mg}$. There has been research that suggests half the dose of tPA is as effective as the current recommended dose and is associated with less bleeding. One study looked at improvement in RV function and lung perfusion, and reduction in clot burden. It demonstrated
Table 3 Doses of fibrinolytic therapy [28]

\begin{tabular}{ll}
\hline Fibrinolytic & Dose \\
\hline $\begin{array}{c}\text { Recombinant } \\
\text { tPA }\end{array}$ & $\begin{array}{c}100 \mathrm{mg} \text { over } 2 \mathrm{~h}(10 \mathrm{mg} \text { bolus followed by } 90 \mathrm{mg} \\
\text { over } 2 \mathrm{~h})\end{array}$ \\
Streptokinase & $\begin{array}{c}250,000 \mathrm{iu} \text { over } 30 \mathrm{~min} \\
\text { Urokinase }\end{array}$ \\
$\begin{array}{c}4,400 \mathrm{IU} / \mathrm{kg} \text { over } 10 \mathrm{~min} \text { followed by } 4,400 \mathrm{IU} / \mathrm{kg} / \mathrm{h} \\
\text { infusion for } 12 \mathrm{~h}\end{array}$ \\
Tenecteplase & $30-50 \mathrm{mg}$ bolus over $5 \mathrm{~s}$ (weight based) \\
\hline
\end{tabular}

Table 4 Absolute and relative contraindications to fibrinolytic therapy [23, 24]

\begin{tabular}{ll}
\hline Absolute contraindications & $\begin{array}{l}\text { Relative } \\
\text { contraindications }\end{array}$ \\
\hline $\begin{array}{l}\text { History of intracranial hemorrhage } \\
\text { Known intracranial neoplasm, } \\
\text { arteriovenous malformation or } \\
\text { aneurysm }\end{array}$ & $\begin{array}{l}\text { Recent internal bleeding } \\
\text { Recent surgery }\end{array}$ \\
$\begin{array}{l}\text { Significant head trauma } \\
\text { Active internal bleeding }\end{array}$ & $\begin{array}{l}\text { Recent trauma } \\
\text { Venipuncture at non- } \\
\text { compressible site }\end{array}$ \\
$\begin{array}{l}\text { Known bleeding disorder } \\
\text { Uncontrolled } \\
\text { Intracerebral or intraspinal surgery } \\
\text { within last } 3 \text { months }\end{array}$ & $\begin{array}{c}\text { Diabetic retinopathy } \\
\text { Cerebrovascular accident within last } \\
2 \text { months }\end{array}$ \\
& Pregnancy \\
& Age $>75$ years \\
\hline
\end{tabular}

statistically similar outcomes in the 50-mg group compared to the 100-mg group, with fewer bleeding complications [29]. In this study, the lower dose tPA reduced bleeding episodes especially in patients $<65 \mathrm{~kg}$ or with BMI $<24$ [29]. See Table 3 for fibrinolytic dosing guidelines.

\section{Other Considerations}

Additional treatment options include surgical embolectomy and catheter directed fibrinolysis. These options are reserved for patients who are hemodynamically unstable and have absolute contraindication to systemic fibrinolysis, or when systemic fibrinolysis has failed to improve hemodynamics [2•]. However, in most clinical settings, these treatment options are not typically available.

In terms of long-term treatment, therapy with vitamin $\mathrm{K}$ antagonists is generally continued for 3 months if the identified risk factor is temporary or reversible. Longer or indefinite treatment should be considered in those with active cancer, unprovoked pulmonary embolism, and recurrent venous thromboembolism [2•]. IVC filters are placed in patients who have contraindications to anticoagulation therapy. 


\section{Conclusion}

Acute PE is a common and life-threatening condition encountered in all areas of medicine, especially in the emergency department. Once diagnosis is confirmed, patients should be risk-stratified into one of three categories: massive PE (high-risk), submassive PE (intermediaterisk), and low-risk PE. Decisions regarding treatment are highly dependent on this risk stratification. The treatments for massive and low-risk PE are typically straightforward, as there is strong supporting evidence in those cases. For massive PE, immediate fibrinolytic therapy in addition to anticoagulation should be administered, while in low-risk $\mathrm{PE}$, anticoagulation alone is sufficient. The group with the most controversy is treatment for submassive PE. There is agreement these patients should universally receive anticoagulation, however, there is less evidence to support fibrinolysis. While there is minimal evidence regarding a decrease in mortality, there is strong evidence that use of fibrinolytics more rapidly restores RV function and pulmonary perfusion, which may offer improvements in morbidity and clinical outcomes. Clinicians should consider fibrinolysis in submassive PE with elevated cardiac biomarkers, echocardiographic or CT evidence of RVD, or in those with refractory hypoxia and high clot burden. Further work is needed, particularly in how patients are risk-stratified, in terms of PE and bleeding risk, so that we can further identify those patients with submassive PE who would benefit from fibrinolysis.

\section{Compliance with Ethics Guidelines}

Conflict of Interest Alicia Pilarski and Shanna Paul have no conflicts of interest to declare.

Human and Animal Rights and Informed Consent This article does not contain any studies with human or animal subjects performed by any of the authors.

\section{References}

Recently published papers of particular interest have been highlighted as:

- Of importance

1. - Lankeit M, Konstantinides S. Thrombolytic therapy for submassive pulmonary embolism. Best Pract Res Clin Haematol. 2012;25(3):379-89. doi:10.1016/j.beha.2012.06.005. In this paper, the focus is on the definition and management of submassive pulmonary embolism.

2. Agnelli G, Becattini C. Acute pulmonary embolism. N Engl J Med. 2010;363(3):266-74. doi:10.1056/NEJMra0907731. As a review paper, this article discusses the most current diagnosis, risk stratification and treatment of acute pulmonary embolism.
3. Bruinstroop E, van de Ree MA, Huisman MV. The use of D-dimer in specific clinical conditions: a narrative review. Eur J Intern Med. 2009;20(5):441-6. doi:10.1016/j.ejim.2008.12.004.

4. van Belle A, Büller HR, Huisman MV, Huisman PM, Kaasjager K, Kamphuisen PW, Kramer MH, Kruip MJ, Kwakkel-van Erp JM, Leebeek FW, Nijkeuter M, Prins MH, Sohne M, Tick LW, Christopher Study Investigators. Effectiveness of managing suspected pulmonary embolism using an algorithm combining clinical probability, D-dimer testing, and computed tomography. JAMA. 2006;295(2):172-9.

5. Sostman HD, Stein PD, Gottschalk A, Matta F, Hull R, Goodman L. Acute pulmonary embolism: sensitivity and specificity of ventilation-perfusion scintigraphy in PIOPED II study. Radiology. 2008;246(3):941-6. doi:10.1148/radiol.2463070270.

6. Stein PD, Chenevert TL, Fowler SE, Goodman LR, Gottschalk A, Hales CA, Hull RD, Jablonski KA, Leeper KV Jr, Naidich DP, Sak DJ, Sostman HD, Tapson VF, Weg JG, Woodard PK, PIOPED III (Prospective Investigation of Pulmonary Embolism Diagnosis III) Investigators. Gadolinium-enhanced magnetic resonance angiography for pulmonary embolism: a multicenter prospective study (PIOPED III). Ann Intern Med. 2010;152(7):434-43, W142-3. doi:10.7326/0003-4819-152-7-201004060-00008.

7. - Tapson VF. Thrombolytic therapy for acute pulmonary embolism. Semin Thromb Hemostat. 2013;39(4):452-8. doi:10.1055/s0033-1334145. Recently published article that discusses the risks and benefits for treating submassive acute pulmonary embolism, as well as discusses various options for fibrinolysis.

8. Goldhaber SZ, Visani L, De Rosa M. Acute pulmonary embolism: clinical outcomes in the International Cooperative Pulmonary Embolism Registry (ICOPER). Lancet. 1999;353(9162):1386-9.

9. Kucher N, Rossi E, De Rosa M, Goldhaber SZ. Massive pulmonary embolism. Circulation. 2006;113(4):577-82.

10. Kasper W, Konstantinides S, Geibel A, Olschewski M, Heinrich F, Grosser KD, Rauber K, Iversen S, Redecker M, Kienast J. Management strategies and determinants of outcome in acute major pulmonary embolism: results of a multicenter registry. J Am Coll Cardiol. 1997;30(5):1165-71.

11. Steering Committee. Single-bolus tenecteplase plus heparin compared with heparin alone for normotensive patients with acute pulmonary embolism who have evidence of right ventricular dysfunction and myocardial injury: rationale and design of the Pulmonary Embolism Thrombolysis (PEITHO) trial. Am Heart J. 2012;163(1):33-38.e1. doi:10.1016/j.ahj.2011.10.003.

12. Torbicki A, Perrier A, Konstantinides S, Agnelli G, Galiè N, Pruszczyk P, Bengel F, Brady AJ, Ferreira D, Janssens U, Klepetko W, Mayer E, Remy-Jardin M. Bassand JP; ESC Committee for Practice Guidelines (CPG). Guidelines on the diagnosis and management of acute pulmonary embolism: the Task Force for the Diagnosis and Management of Acute Pulmonary Embolism of the European Society of Cardiology (ESC). Eur Heart J. 2008;29(18):2276-315. doi:10.1093/eurheartj/ehn310.

13. Kearon C, Akl EA, Comerota AJ, Prandoni P, Bounameaux H, Goldhaber SZ, Nelson ME, Wells PS, Gould MK, Dentali F, Crowther M, Kahn SR, American College of Chest Physicians. Antithrombotic therapy for VTE disease: antithrombotic therapy and prevention of thrombosis, 9th ed: American college of chest physicians evidence-based clinical practice guidelines. Chest. 2012;141(2 Suppl):e419S-94S. doi:10.1378/chest.11-2301.

14. Konstantinides S. Clinical practice. Acute pulmonary embolism. N Engl J Med. 2008;359(26):2804-13. doi:10.1056/NEJMcp0804570.

15. Kucher N, Rossi E, De Rosa M, Goldhaber SZ. Prognostic role of echocardiography among patients with acute pulmonary embolism and a systolic arterial pressure of $90 \mathrm{mmHg}$ or higher. Arch Intern Med. 2005;165(15):1777-81.

16. Sanchez O, Trinquart L, Colombet I, et al. Prognostic value of right ventricular dysfunctionin patients with haemodynamically 
stable pulmonary embolism: a systematic review. Eur Heart J. 2008;29:1569-77.

17. Lu MT, Cai T, Ersoy H, Whitmore AG, Quiroz R, Goldhaber SZ, Rybicki FJ. Interval increase in right-left ventricular diameter ratios at $\mathrm{CT}$ as a predictor of 30-day mortality after acute pulmonary embolism: initial experience. Radiology. 2008;246(1):281-7.

18. Vedovati MC, Becattini C, Agnelli G, Kamphuisen PW, Masotti L, Pruszczyk P, Casazza F, Salvi A, Grifoni S, Carugati A, Konstantinides S, Schreuder M, Golebiowski M, Duranti M. Multidetector CT scan for acute pulmonary embolism: embolic burden and clinical outcome. Chest. 2012;142(6):1417-24.

19. Becattini C, Vedovati MC, Agnelli G. Prognostic value of troponins in acute pulmonary embolism: a meta-analysis. Circulation. 2007;116(4):427-33.

20. Klok FA, Mos IC, Huisman MV. Brain-type natriuretic peptide levels in the prediction of adverse outcome in patients with pulmonary embolism: a systematic review and meta-analysis. Am J Respir Crit Care Med. 2008;178(4):425-30. doi:10.1164/rccm. 200803-459OC.

21. Binder L, Pieske B, Olschewski M, Geibel A, Klostermann B, Reiner $\mathrm{C}$, et al. N-terminal pro-brain natriuretic peptide or troponin testing followed by echocardiography for risk stratification of acute pulmonary embolism. Circulation. 2005;112:1573-9.

22. Puls M, Dellas C, Lankeit M, Olschewski M, Binder L, Geibel A, Reiner C, Schäfer K, Hasenfuss G, Konstantinides S. Heart-type fatty acid-binding protein permits early risk stratification of pulmonary embolism. Eur Heart J. 2007;28(2):224-9.

23. Fengler BT, Brady WJ. Fibrinolytic therapy in pulmonary embolism: an evidence-based treatment algorithm. Am J Emerg Med. 2009;27(1):84-95.

24. Vyas PA, Donato AA. Thrombolysis in acute pulmonary thromboembolism. South Med J. 2012;105(10):560-70.

25. Fasullo S, Scalzo S, Maringhini G, Ganci F, Cannizzaro S, Basile I, Di Pasquale P. Six-month echocardiographic study in patients with submassive pulmonary embolism and right ventricle dysfunction: Comparison of thrombolysis with heparin. Am J Med Sci. 2011;341(1):33-9.

26. Piazza G, Goldhaber SZ. Management of submassive pulmonary embolism Circulation. 2010;122(11):1124-9.

27. Becattini C, Agnelli G, Salvi A, Grifoni S, Pancaldi LG, Ene I, TIPES Study Group. Bolus tenecteplase for right ventricle dysfunction in hemodynamically stable patients with pulmonary embolism. Thromb Res. 2010;125(3):e82-6.

28. Micromedex ${ }^{\circledR}$ Healthcare Series [Internet database]. Greenwood Village, Colo: Thomson Healthcare. Updated periodically.

29. Wang C, Zhai Z, Yang Y, China Venous Thromboembolism (VTE) Study Group, et al. Efficacy and safety of low dose recombinant tissue-type plasminogen activator for the treatment of acute pulmonary thromboembolism: a randomized, multicenter, controlled trial. Chest. 2010;1372:254-62. 